\title{
Quaestiones de quolibet, de Santiago de Viterbo
}

No deja de extrañar la falta de obras impresas del Beato Santiago de Viterbo. ¿Acaso su orientación agustiniana influyó en este olvido? Lo cierto es que sólo la obra De regimine cbristiano ${ }^{1}$ ha sido publicada. Ha visto también la luz pública una disertación con el título Valor possibilium apud $S$. Thomam, Henricum Gandavensem et $B$. Jacobum de Viterbo ${ }^{2}$, donde únicamente se transcriben citas de este autor. Por último, Grabmann ha publicado parte de la Quaest. 4 del Quodl. 1 acerca de la distinción real ${ }^{3}$. Todo lo demás es todavía material de archivo si se exceptúan las citas esporádicas necesarias en los estudios que sobre este autor se han hecho. De boca del ilustre P. Pelster, S. J. en cierta ocasión oímos personalmente una queja por el abandono en que estaban quedando tales manuscritos. $Y$, sin embargo, he aquí lo que dice el P. D. Gutiérrez: "Nullus alius inter doctores antiquos scholae aegidianae fuit a posteritate ita iniuste praetermissus sicut B. J. de Viterbio, Magno quidem nomine et auctoritate per totum saeculum XIV et adhuc primis annis saeculi XV pollebat, ut apparet ex copia manuscriptorum ipsius opera continentium et ex quamplurimis citationibus apud doctores propriae scholae, pene quos ipse "luminare minus" Ordinis nostri, et etiam apud doctores aliarum scholarum, qui saepe illum impugnant, quandoque vero tacite transcribunt" 4 .

Para enmendar de alguna manera este olvido y estas deficiencias nos hemos propuesto transcribir las cuestiones que han sido objeto de los estudios que ocasionalmente hemos llevado a cabo acerca del pensamiento filosófico del Beato. Vaya por delante una alusión siquiera acerca de los manuscritos que nos han proporcionado los materiales de primera mano ${ }^{5}$.

De regimine christiano, Ed. H. X. Arquillière, París 1926.

J. BENES, Rovigo 1927.

Acta hebdomadis thomisticae, Romae 1924, 130-190.

4 D. GuTIÉRREZ, De Jacobi Viterbiensis O.S. A. vita, operibus et doctrina theologica, Romae 1939.

5 F. CASADo, "El pensamiento filosófico de Santiago de Viterbo": La Ciudad de Dios 163 (1951) 437-454; 164 (1952) 301-331; 165 (1953) 103-144, 283. $302,489-500$. 
NúMERo,-Sobre el número de los manuscritos hay que decir que contamos con una verdadera profusión de los mismos: Se encuentran ejemplares en Italia, Francia, Alemania y España.

UBICACIÓN.-Brevemente hacemos una reseña del lugar donde se encuentran: Bordeaux, Bibl. de la Ville, cod. 167 (Quodl. I, ff. 117-146); Quodl. II, ff. 146-174). Este códice contiene además los otros dos Quodlibetos (III y IV). Padua, Bibl. della Universitá, cod. 2.006, ff. 50-142; contiene además el tercer quodlibeto. Angers, cod. 223, ff. 1-119. Berlin, Staatsbibl., cod. 468, ff. 77-125. Cracovia, Bibl. Univers. Iagellon., cod. 1.577, ff. 96-132. Erfurt, Bibl. Amplon., cod. F. 321, ff. 62-92. Erlangen, Bibl. Univers., cod. 368, ff. 123-161. Florencia, Bibl. Laurenz, cod. 2, ff. 1-101. Nápoles, Bibl. Naz., cod. VIII.E 44, ff. 1-73. Padua, Bibl. Anton., cod. 373. París, Bibl. Nat. lat., cod. 14.569, ff. 119-187; cod. 15.362, ff. 1-69; cod. 15.851, ff. 81-152; Bibl. Nat. nuov., cod. 1.470; Bibl. Naz., cod. 889, ff. 105-183; cod. 3.512, ff. 1-59. Troyes, cod. 269. Vaticano, Vat. Borgh., cod. 121, ff. 183-223; Vat. lat., cod. 982, ff. 1-79; Vat. Ottob. lat., cod. 196, ff. 75-122. Madrid, Bibl. Nacion., cod. 379 (sólo el Quodl. I). París, Nat. lat., cod. 15.350, ff. 291-337. Vaticano, Vat. lat., cod. 772, ff. 64-68; Vat. lat., cod. 5.745, ff. $34-38$.

AUTENTICIDAD.-Respecto de la crítica histórica de dichos Quodlibetos anotamos lo siguiente: la autenticidad estuvo siempre plenamente garantizada. Los testimonios son tan antiguos como el autor del original. Se encuentran citados: en el Indice de la Universidad de París del año 1304 (Santiago de Viterbo muere en el 1307); en los Catálogos de la biblioteca del convento dominico de Tarvisio en el 1347 y de la biblioteca pontificia de Avignon de 1357. Tenemos además referencias de los Quodl. II y III sobre el Quodl. I.

ANTIGÜEDAD.-Pertenecen todos ellos al siglo XIV y son de materia membranácea.

TIEMPo DE COMPosición.-Se fija al principio del magisterio en París del Beato Santiago de Viterbo (1293 a 1299), mientras fue Maestro actu regens en aquella universidad.

TRANSCRIPCIÓN,-La transcripción está hecha directamente sobre el manuscrito que se encuentra en la biblioteca Vaticana con la indicación: Manuscrito Ottoboniano latino 196. Algunas pequeñas omisiones de este manuscrito las hemos corregido sirviéndonos de otro manuscrito también de la biblioteca Vaticana, el Vaticano latino 982. 


\title{
QUODLIBETO I (Q. 12) *
}

\author{
[CUESTIÓN ACERCA DE LA EXISTENCIA Y NATURALEZA DEL ENTENDIMIENTO \\ AGENTE.]
}

(f. 91 ra). Duodecimo quaeritur utrum intellectus agens sit aliquid animae. Et videtur quod non. Quod enim est substantia actu ens non est aliquid animae tamquam eius pars potentialis; sed intellectus agens est substantia actu ens, sicut dicit Aristoteles in III de anima; igitur non est aliquid animae.

In contrarium arguitur sic secundum Philosophum in III de anima: Sicut in omni natura sic et in anima est ponere duas differentias; haec sunt: intellectus possibilis et agens. Differentiae autem alicuius rei sunt aliquid illius; igitur intellectus agens est aliquid animae.

(f. $91 \mathrm{rb}$ ). Ad huius quaestionis dissolutionem procedendum est hoc modo: primo, enim, ad huius quaestionis intellectum distinguendum est de intellectu agente; secundo, videndum est quid de intellectu agente opinati sunt tam antiqui quam posteriores doctores, et quid sit in eorum opinionibus dubitabile; tertio, tangendus est quis alius modus dicendi de intellectu agente satis rationabilis; quarto etiam quia iste modus dubitationem videtur habere, ideo circa ipsum movenda quaedam dubia et solvenda.

\section{[SENTIDOS DE LA EXPRESIÓN "ENTENDIMIENTO AGENTE".]}

Quantum igitur ad primum sciendum est quod intellectus agens potest dupliciter accipi : uno modo potest accipi respectu cuiuscumque producti; consequenter et hoc modo omnis intellectus producens aliquid dicitur intellectus agens; sic enim ipsa prima omnium causa dicitur intellectus agens, quia omnia producit et movet. Unde et Anaxagoras, intellectum segregantem res ex illo chaos quod ipse posuit et imperantem, vocavit intellectum agentem secundum praedictum modum; sic etiam intellectus cuiuslibet artificis dicitur intellectus agens quia producit aliquid extra; alio modo dicitur intellectus agens respectu ipsius actionis [intellectualis (Vat.)] specialiter: et hoc modo dicitur intellectus agens ille intellectus cuius virtute fit actio intelligibilitatis in nobis. Cum enim simus intelligentes quan-

* La transcripción está hecha sobre el Ms. Ottob. Vat. lat. 196. 
doque quidem in actu, quandoque vero in potentia, nec procedat aliquid de potentia in actum nisi per aliquod agens, oportet ponere aliquid quod agit in nobis actionem intelligendi, quod quidem agens potest esse de genere intellectus, quia quod non est naturae intellectualis non potest actionem intellectualem producere. Et ideo istud agens intellectus agens vocatur. Primo igitur modo non procedit quaestio praesens de intellectu agente, sed secundo modo, ut intelligatur hoc modo quaestio: utrum, scil., intellectus agens et intellectus qui causat in nobis actionem intelligibilem sit aliquid animae tamquam eius pars potentialis, vel sit aliqua substantia intellectualis per se subsistens. His autem praemisis ad intellectum quaestionis, quid de intellectu agente sint opinati tam antiqui philosophi quam posteriores doctores.

\section{[Opiniones de Platón, Alejandro, Averroes, Temistio, Juan el Gramático (FILOPÓN) Y "ALGUNOS MODERNOS" (S. TOMÁs Y EGIDIO).]}

Propter quod sciendum quod Johannes Grammaticus super III de anima plures opiniones recitat de intellectu agente. Nam, ut ait, quidam dixerunt intellectum agentem esse conditorem, scil, Deum ipsum; et hoc dicitur sensisse Plato (sic); propter quod intellectum agentem esse Deum qui est lux vera, quae illuminat omnem hominem venientem in hunc mundum, moti fortasse ad hoc dicendum explicitis verbis B. Augustini, quae hoc insinuare videntur. Secundum igitur hanc opinionem intellectus agens non est aliquid animae sicut eius potentia vel pars. Sed licet hoc indubitanter sit verum, eo quod Deus in anima et in rebus omnibus principaliter operetur, non tamen videtur esse sufficiens. Actio enim Dei operantis in rebus non excludit agentia specialia quibus de sua bonitate communicat dignitatem causandi; et ideo, sicut in aliis rebus naturalibus et maxime perfectis, praeter universalia agentia ponuntur agentia specialia, similiter in anima, quae est quid perfectum inter omnia inferiora, praeter agens qui est Deus videtur esse ponenda virtus aliqua specialis creata quae causat intellectualem operationem. Et ideo est alia opinio quorumdam dicentium intellectum agentem esse intellectum quemdam inferiorem quidem divino intellectui, superiorem autem intellectu nostro et secundum gradum nec inmediate suppositum, cuius virtute fit in nobis intellectualis operatio; et hoc vel secundum quamdam unionem ipsius ad nos, sicut posuit Alexander et Averroes, vel per influxum formarum intelligibilium ab ipso in nos, sicut posuit Avicenna. Et secundum hanc etiam opinionem intellectus agens non est aliquid animae tamquam eius pars potentialis. Sed haec opinio neque sufficiens neque conveniens esse videtur: sufficiens quidem non est quia omnes intellectuales substantiae quae sunt supra animam inter causas universales numerantur; praeter ipsas oportet ponere in anima specialem virtutem agentem, intelligendo sicut supra dictum est de Deo; conveniens etiam non est eo quod talis 
unio illius intellectus ad nos vel influxus ipsius in nos, quale posuerunt praedicti philosophi, sanae doctrinae repugnat, sicut a magnis doctoribus est sufficienter ostensum. Posset tamen dici (quod) substantiae spirituales agentes in nos aliquo modo quantum ad intellectum, in quantum nos de aliquibus docent

(f. $91 \mathrm{va}$ ) non quidem principaliter operando sed coadiuvando. Iste autem modus agendi praeexigit virtutem aliquam intellectualem in nobis agentem actionem intellectualem, et hoc proprie dicitur intellectus agens. Et propter hoc est alia opinio aliquorum qui posuerunt intellectum agentem non esse aliquid ab anima separatum in ipsa existens. Dicunt enim in ipsa anima esse duplicem intellectum: unum quidem qui in potentia est et dicitur possibilis, alium vero qui actu et agens vocatur; et eum quem potentiam dicunt semper in anima existere; illum vero qui actu de foris ingredi et alium perficere; eum qui potentia, possibilis. Et haec fuit opinio quorumdam platonicorum, qui non recte accipientes quod a Platone dictum est "animam semper moveri", et inferentes nomen motus ad cognitionem, posuerunt animam semper intelligere per intellectum qui est actu; cuius oppositum exprimitur quia nec pueri, nec dormientes, nec mente alieni intelligunt. Huic autem opinioni videtur esse vel eadem vel propinqua opinio Themistii, sicut in expositione sua super librum $D e$ anima. Aristoteles posuit enim in anima esse duplicem intellectum, scil., possibilem et factivum, utrumque potentialem partem ipsius animae, utrumque separatum, utrumque inmortale et perpetuum; factivum autem honorabiliorem et a quo principaliter est homini esse. Utrumque dixit etiam esse intelligentem, sed factivum semper actu, possibilem autem non semper; et quod in possibili in actu sunt intelligibilia simpliciter, multipliciter et diversim; in factivo autem simpliciter et unitive; et in factivo, scil., ipse est essentia et actus, in possibili dicit vero essentia ab actu, et utrumque posuit multiplicari secundum multiplicationem hominum, licet reducantur omnes in unum primum intellectum, scil., divinum a quo alii derivantur, unum, ait, quod est unus illustrans primus, illustrati et illustrantes sunt plures, sicut sol quidem unus est, [lumen (Vat)] autem ab ipso derivatum dividitur et multiplicatur. Posuit etiam quod licet uterque intellectus sit [in ipsa Vat)] anima et pars eius potentialis, tamen magis est animae connaturalis; et quod possibilis cum de se sit in potentia intelligens activo illustrante sibi, qui comparatur ad ipsum sicut ars ad materiam, non tamen est ars materiae exterioris sicut aedificativa [respectu (Vat)] lignorum, sed investitur intellectus factivus toti potentiae intellectivae ac si ars aedificativa esset in lignis, et sic fit unum ex possibili et factivo, sicut ex materia et forma aliquo modo. Sed haec etiam opinio dubitabilis est. Cum onim anima per intellectum factivum omnia intelligat actu, praeter innecessarium videtur et superfluum inducere alium qui dicatur possibilis, nisi quis dicere velit quod possibilis intellectus in anima ponitur propter hoc quod est unibilis corpori in quo acquirit perfectionem intelligibilium et possibilem intellectum illustrante factivo 
Sed hoc etiam non videtur rationabiliter dici, quia tunc in anima esset duplex intelligendi modus simul respectu eorumdem obiectorum, et hoc naturaliter. Et praeterea cum anima separatur a corpore tunc saltem videtur intellectum possibilem esse otiosum et frustra, cum non perficiatur a factivo qui est in actu nisi secundum ordinem ad phantasmata, ut videlicet quia sine phantasmate nihil intelligit; vel si ponit ab ipso perfici sine habitudine ad phantasmata, vel unus videtur supervacue poni. Amplius, sicut dictum est, experimur nos non semper intelligere, quod non esset si semper esset in anima intellectus in actu. Si autem aliquis dicat quod intelligimus, quidem non perpendimus, irrationabiliter dicitur; non enim convenit intelligi aliquem non perpendentem. Sunt autem et alia multa quae induci possent contra praedictum modum ponendi. Ideo est quarta opinio quam ipse Johannes Grammaticus magis acceptat. Dicit enim quod intellectus agens et possibilis unus et idem est, perfecto et imperfecto differens, quod sic est intelligendum : sicut enim aliquid dicitur possibile eo quod est in potentia, sic dicitur agens in quantum est actu et facit aliquid actu. Intellectus autem noster quandoque quidem est potentia, et quod huiusmodi dicitur possibilis; sed intellectus qui est in actu, per quem ille qui est potentia in actum (ducitur), dicitur agens; iste autem est intellectus doctoris qui et ipse fuit ductus de potentia in actum per alium intellectum actu existentem, sicut etiam contigit in generatione aliarum rerum naturalium, et hoc igitur tam intellectus agens quam possibilis sunt aliquid animae et sunt in eadem secun-

(f. $91 \mathrm{vb}$ ) dum numerum sed eadem secundum speciem et differunt secundum perfectum et imperfectum; unde dicit Aristoteles in $1^{\circ}$ de anima: quod ille qui est potentia sciens addiscit et accipit scientiam ab actu ente, a didascalo. Se vero dicatur quod non semper sit aliquis de potentia intelligente actu intelligens per doctrinam alterius, sed quandoque per inventionem propriam, respondit ad hoc Johannes Grammaticus quod intellectus possibilis saltem principia universalia accipit a doctore et tantum secundum illa principia potest seipsum ducere in actum quantum ad alia. Haec autem opinio, etsi vera sit, non tamen est sufficiens. Sic enim doctor communicat scientiam sicut medicus sanitatem. Medicus autem sanat non principaliter sed amminiculando; virtus autem vere in eo qui sanatur est agens principaliter sanans. Sequitur igitur (quod) illud quod principaliter ad acquisitionem scientiae est aliquod principium intra in anima illius qui addiscit; doctor autem cooperatur coadiuvando. Quare, praeter intellectum doctoris oportet ponere aliquid activum in eo qui ducitur de potentia in actum secundum intelligere, non solum quantum ad intelligibilia vel conclusiones sed etiam quantum ad prima intelligibilia quae sunt universalia principia, quorum non est proprie doctrina cum sint naturaliter nota, sicut Commentator II Met. Ideo est quinta opinio quam plures doctores moderni sequuntur, quod videlicet intellectus agens est aliquid animae et est in anima sicut quaedam eius potentia realiter differens ab 
intellectu possibili, ita quod in anima sint duae potentiae per quarum unam, scil., intellectum possibilem, est in potentia ad recipiendam intellectualem perfectionem, per agentem vero agit et efficit perfectionem intellectualem in quantum per ipsum quae sunt intelligibilia in potentia funt actu intelligibilia per abstractionem a materialibus conditionibus. Hoc autem sic declaratur: cum enim intellectus sit in potentia ad intelligibilia, oportet quod ipsa intelligibilia moveant intellectum nostrum possibilem; quod autem non est actu, non movet. Cum igitur obiectum intelligibile, quod est universale, non sit actu, quia universale non est aliquid extra animam nisi in potentia, oportet ponere aliquem intellectum in ipsa anima per quam fiat actu intelligibile, et hic intellectus est intellectus agens; et ideo Plato, qui posuit universalia separata secundum rem, non indiguit ponere intellectum agentem. Qualiter autem intellectus agens faciat actu intelligibilia quae sunt potentia intelligibilia, sic patet: non enim agit in ipsas res quae sunt potentia intelligibiles secundum quod sunt extra animam sed secundum quod earum similitudines recipiuntur in viribus sensitivis quae etiam sunt potentiae quaedam eiusdem animae. Hoc enim modo intellectus agens potest ad res attingere in quantum coriunguntur earum similitudinibus quae sunt in aliqua potentia sensitiva cui adest intellectus agens sicut ipsa animae essentia in qua fundatur; quamvis autem rerum corporalium similitudines recipiantur insensitive sine materia non tamen sine conditionibus materialibus. Et ideo res ipsae et secundum quod sunt sensibilia sunt potentia intelligibilia, nec possunt movere intellectum possibilem secundum quod huiusmodi sunt. Cum igitur rerum similitudines perveniant ad virtutem phantasticam a qua immediate accipit intellectus, tunc ipse intellectus agens irradiat et illustrat phantasmata per quam illustrationem abstrahuntur a conditionibus materialibus, ac per hoc fiunt actu intelligibilia et sic possunt intellectum possibilem immutare et facere ipsum in actu. Sic igitur ad hoc quod intellectus possibilis fiat in actu requiruntur phantasmata, quae sunt similitudines quaedam determinatarum rerum, et requiritur intellectus agens cuius virtute phantasmata possunt movere possibilem intellectum. Non quod intellectus agens faciat aliquan dispositionem dispositivam in ipsis phantasmatibus, sed quia ex quadam spirituali coniunctione ipsius ad phantasmata separantur et abstrahuntur a conditionibus materialibus non secundum rem sed secundum immutandi rationem, in quantum immutant intellectum possibilem quantum ad essentiam rei et non quantum ad conditiones materiales; et hoc modo dicuntur abstrahi species a phantasmatibus. Et hoc modo declaratur tali exemplo: ponatur enim quod lac, quod est album et dulce, per seipsum absque praesentia luminis non posset se facere in medio secundum speciem albi quin faceret se secundum speciem dulcis, sed lumine praesente fieri posset in medium secundum speciem albi absque specie dulcis. Tunc

(f. 92 ra) enim diceretur fieri abstractionem albi a dulci non secundum rationem essendi sed solum secundum rationem immutandi; similiter dicendum est 
de abstractione quam facit intellectus agens ab ipsis phantasmatibus. Sed iste modus dicendi, licet sit possibilis quantum ad hoc quod ponit intellectum agentem esse aliquid animae, quandam animae potentiam, tamen est dubitabilis quantum ad hoc quod ponit intellectum agentem esse potentiam differentem re absoluta $a b$ intellectu possibili et etiam quantum ad modum agendi quem assignat eidem. Nam, ut videtur, illa quae Commentator Averroes dicit de intellectu agente separato, haec opinio nititur applicare ad quandam potentiam in nobis, quae applicatio an convenienter fieri possit satis est dubium. Item si propter hoc ponatur intellectus agens quod phantasmata secundum se non possunt immutare intellectum possibilem, cum potentia sint intellegibilia ratione materialitatis, eadem ratione ponendus est sensus agens quia sensibilia sunt intentiones sensatae in potentia, et ideo non possunt secundum se absque aliquo agente immutare sensum. Sicut enim intellectus excedit phantasmata quia intellectus est virtus immaterialis, phantasmata vero materialia, sic sensus excedit sensibile quia sensus est virtus vitalis, sensibilis autem est non vivum, et sensibile est cum materia, sensus autem suscipit sine materia. Aeque enim videtur inconveniens dicere quod actio sensus causetur a sensibili secundum se sicut quod actio intellectus causetur a phantasmate secundum se. Et ideo Averrois hoc attendens dicit et probat II de anima quod necesse est hoc ponere in intellectu. Sed, ut dicit, Aristoteles tacuit hoc in sensu quia latet magis quam in intellectu. Cum igitur praedicta opinio non ponat sensum agentem videtur quod nec debeat ponere intellectum agentem, vel si ponat agens in intellectu debet ponere in sensu. Amplius cum substantia non sit sensibilis nisi per accidens, similitudo substantiae non potest esse in phantasmate nisi per accidens; similitudo autem substantiae per accidens non potest causare in alio similitudinem substantiae per se, nec potest fieri virtute intellectus agentis illud quod est per accidens per se. Quare non videtur posse salvari secundum praedictum modum dicendi de intellectu agente quomodo intellectus intelligat substantiam et universaliter omnia quae sunt per se inintelligibilia. Adhuc, cum intellectus agens sit potentia naturaliter indita, oportet ipsum ponere in anima respectu omnium intelligibilium et non tantum respectu aliquorum; oportet enim quod deserviat animae in intelligendo non solum dum est corpori coniuncta sed etiam cum est a corpore separata. Sed ponendo intellectum agenten modo supradicto non est animae necessarius nisi respectu obiectorum materialium et solum dum est coniuncta corpori corruptibili. Est igitur praedictus modus dubitabilis. Sunt et etiam alia plura quae dubitationem faciunt contra iam modum praedictum. 
[OPINIÓN PROPIA QUE CREE SER DE MUCHOS ANTIGUOS Y ESPECIALMENTE EN CONSONANCia CON la MENTE de SAN Agustín y dE Boecio. TeORía de las "IDONEIDADES" O ACTUALIDADES INCOMPLETAS.]

Narratis igitur summarie diversis opinionibus de intellectu agente, tertio tangendum est quidam alius modus dicendi de ipso, qui mihi apparet inter caeteros esse rationabilior. Est multorum antiquorum doctrina et maxime Bti. Augustini et Boetii satis consonus. Est autem modus talis: intellectus agens est quidem aliqua potentia animae rationalis, non tamen alia secundum rem absolutam ab intellectu possibili, sed una et eadem potentia dicitur et possibilis et agens licet non eodem modo. Quod quidem faciliter potest intelligi et explicari si considerentur quae superius in quaestione de voluntate dicta sunt. Sicut enim potentia voluntatis dicitur movens et mota, et activa et passiva, sic etiam in intellectu per omnia dicendum est hoc, excepto quod in sua motione libera est, intellectus autem non. Unde intuentibus quae in illa quaestione sunt dicta non esset oportunum hic multa adducere. Verumtamen suppositis his quae ibi sunt declarata praeambulis ut aliqua eorum applicentur magis ad intellectum de quo est praesens quaestio consideranda, quod anima respectu huiusmodi actionum quae sunt intelligere, sentire et appetere habet se aliquo modo passive ex hoc ipso quod quandoque est in potentia secundum hoc, quandoque in actu, non tamen pure passive sed et active, quod taliter potest declarari: primo ex proprietate actionum vitalium; omnis enim operatio vitalis est a principio activo intrinseco, non autem ab alio nisi $a b$ anima. Minor huius rationis patet; maior sic declaratur: in hoc enim differunt viventia a non viventibus, quod non viventia habent in se

(f. $92 \mathrm{rb}$ ) principium motus per passivum; viventia non solum passivum sed et activum, quod quidem apparet in illis motibus qui sunt communes viventibus et non viventibus, sicut generatio et alteratio et motus localis. Dicuntur enim viventia moveri secundum locum ex se et generari et alterari ex se, sicut dicit Commentator in II Phys. et in VII Metaphy., quia in se habent principium activum istorum motuum; multum magis igitur dicendum est quod respectu motuum qui solis viventibus conveniunt habent in se activum principium quamvis huiusmodi principium debeat aliter sumi quam prinipium in motibus supradictis, sicut et huiusmodi motus qui sunt proprii viventibus sunt alterius rationis et modi quam illi qui sunt communes et non viventibus. Secundo patet idem ex compararatione actionum ad agentem: oportet enim actus proportionari activis potentiis, ita quod actus non excedat activitatem potentiae, ex quo sequitur quod actio vitalis non potest esse nisi a principio activo vitali proprie et proportionate, ut intelligete a principio intellectivo et similiter de aliis. Habet se igitur anima respectu huiusmodi actionum non pure passive sed et active, et magis sunt ab ipsa anima quam ab obiectis. Unde dicit Boetius $\mathrm{V}$ de Consolatione: "in cognoscendo cuncta, 
sua potius facultate quam eorum quae cognoscuntur, utuntur in hoc rationabiliter". Nam ut omne iudicium iudicandi actu existat, necesse est ut suam quisque opinionem [operam (Vat)] non aliena potestate sed propria perficiat. Unde convenienter Boetius excludit et improbat opinionem Stoicorum qui dicebant animam in cognoscendo suam formam habere se pure passive, sicut materia respectu formarum, speculum respectu imaginum, ostendens ex ipsa cognitione huiusmodi operationum animae quod anima se habet respectu earum sicut efficiens et agens. Apparet hoc etiam ex differentia actionum; actionum enim quaedam dicuntur transeuntes, quaedam vero manentes in ipso agente, sicut patet per Phylosophum in II Met.; sed huiusmodi actiones animae sunt manentes in anima et ipsam perficientes; quare ipsa anima habet se active respectu ipsarum; propter quod dicuntur actiones et operationes animae et non obiectorum. Quomodo autem huiusmodi operationes dicantur manentes et quomodo non, in quaestione de voluntate dictum est.

Ostenso igitur quod anima se habet et passive et active respectu huiusmodi operationum, est ulterius considerandum quod non secundum aliud et aliud, sed secundum unam et eamdem potentiam dicitur activa et passiva, quod patet si consideratur qualis est illa potentia secundum quam dicitur anima potentia intelligens et sentiens. Est enim quaedam actualitas incompleta pertinens ad secundam speciem qualitatis quae est potentia naturalis considerata secundum exordium et praeparationem quandam respectu actus ulterioris; unde dicitur aptitudo et idoneitas naturalis ad actum completum. Illud autem quod sic est in potentia secundum quoddam incompletum, movetur ex se ad completum actum non quidem efficienter sed formaliter; et ita secundum idem est passivum et activum, licet non eodem modo nec actione et passione transeunte. Quomodo autem aliquid possit moveri ex se formaliter et quomodo secundum idem possit esse activum et passivum, in quaestione iam dicta de voluntate plenius declaratum est. Unde ad intelligendum quae in hac quaestione tanguntur breviter oportet recurrere ad ea quae ibi sunt plenibus elucidata. Sic igitur est dicendum secundum Anselmum: non solum in voluntate sed etiam in intellectu et sensu distinguitur instrumentum quae est aptitudo quaedam generalis; aptitudines autem instrumenti sunt quaedam potentiae et aptitudines magis speciales fundatae supra illam generalem; usus vero instrumenti est actus potentiae. Sicut igitur voluntas movet se suis actionibus, sic intellectus movet se suis aptitudinibus et similiter sensus; et sicut eadem potentia voluntatis est movens et mota, et activa et passiva, sic etiam eadem potentia intellectiva est activa et passiva, et movens et mota. Eodem itaque modo [et (Vat)] uniformiter ponendum est aliquid activum in huiusmodi omnibus potentiis, quia ipsa potentia cum suis aptitudinibus secundum quod nata est perfici per ulteriores actus dicitur possibilis; secundum vero quod ad illos actus movetur, non quidem efficienter sed formaliter, dicitur agens et una 
(f. 92 va) et eadem potentia diversimode sumpta. Est tamen considerandum quod licet in omnibus huiusmodi potentiis possit hoc modo poni agens et possibilis tamen in intellectu maxime consuetum est dici, quod provenisse videtur ex opinionibus philosophorum ponentium intellectum agentem esse aliquid extrinsecum. Sed ab Augustino et Boetio et aliis antiquis doctoribus non fit huiusmodi distinctio agentis et possibilis circa intellectum magis quam circa sensum, nisi quod ipsum Deum dicunt esse agentem principaliter in intellectu, quod et verum est quia ipse movet intellectum nostrum per modum efficientis, et movet voluntatem quia producit animam cum suis potentiis et aptitudinibus et inde inchoatus [tunc (Vat)] intellectus movet se formaliter; et hoc modo dicitur agens. Item etiam est sciendum quod licet omnes huiusmodi potentiae sint et activae et passivae, secundum aliquem modum tamen quanto potentia est altior et nobilior tanto magis activa est; ideo intellectus magis activus quam sensus, et voluntas magis quam intellectus. Secundum igitur hunc modum dicendi patet quod intellectus agens est aliquid animae, scil., potentia quaedam ipsius per quam anima se movet ad intelligendum non quia virtutem conferat phantasmatibus, magis autem a phantasmatibus excitatur et dicetur infra. Non est alia potentia ab intellectu possibili secundum rem absolutam, sed eadem, differens tamen secundum modum se habendi vel secundum aliquam habitudinem, ut patet ex dictis. Sed quia modus iste pluribus forsitan videtur extraneus et dubius, ideo ad ampliorem intelligentiarn ipsius inducendae sunt quaedam dubitationes circa ipsum solvandae.

[Dificultades CONTRa la opinión de SANTIAgo de Viterbo y SU SOLUCión.]

Primo igitur dubitatur contra hoc quia secundum Philosophum in III de anima intellectus possibilis et agens sunt duae differentiae in anima, quarum una se habet ad aliam sicut ars ad materiam quia possibilis est omnia fieri, agens vero omnia facere. His autem oppositum videtur dicere positio supradicta dum ponit intellectum possibilem et agentem esse unam eamdemque potentiam.

Secundo dubitatur quia, secundum Philosophum in III de anima, anima est sicut tabula rasa in qua nihil est scriptum, quia nihil est actu quantum ad intelligibilia antequam intelligat, cuius contrarium asserit dicta positio dum ponit in anima respectu intelligibilium actualitatem quamdam incompletam, ipsam, scil., potentiam cum suis aptitudinibus, quae et potentiae dicuntur. Et sic videtur incidere ista positio in Platonis dogmata, qui ponit in anima scientiam innatam et habitus latentes, et quod nostrum discere est reminisci, quod et ab Augustino improbatur XII lib. de Trinitate.

Tertio dubitatur quia secundum Philosophum in III de anima sicut sensibilia movent sensum sic phantasmata movent intellectum. Dicitur etiam quod nihil sine phantasmate intelligit anima. Sed secundum praedictam positionem phantasmata 
non movent intellectum sed intellectus movetur ex se; nec etiam videtur per consequens esse necessarium ad intelligendum. Similiter etiam nec sensus videtur esse necessarium, cuius tamen contrarium experimur, quia deficiente sensu, deficit etiam scientia eorum quae ad illum sensum pertinent, et ut sit ad unum dicere, videtur haec positio negare scientiam creari a rebus, quod esset omnino contrarium veritati.

Quarto dubitatur etiam quia haec positio videtur tollere abstractionem per quam id quod est potentia intelligibile fit actu intelligibile, cum tamen Philosophus videatur abstractionem huiusmodi attribuere intellectui agenti,

Quinto dubitatur quia secundum hanc positionem videtur quod anima frustra uniatur corpori, quia si anima acquirit cognitionem intellectualem a rebus per sensus corporeos, in nullo iuvatur a corpore sed magis impeditur, sicut posuit Plato quod anima ex coniunctione ad corpus impeditur et oblivionem quamdam patitur, ex quo ulterius videtur sequi quod magis anima sit propter corpus cum per animam perficiatur, quam corpus propter animam cum per ipsam impediatur. Haec autem sunt inconvenientia, scil., quod anima sit propter corpus quia magis est materia propter forman quam e converso. Sunt autem et alia quae possent facere dubitationem contra praedictam positionem; sed si solvantur quae iam dubitata sunt satis poterit haberi materia ad alia solvenda.

\section{[SOLUCIÓN DE LAS DIFICULTADES.]}

Ad praedictas igitur dubitationes per ordinem dicendum est aliquid, et quia pro magna parte videntur accipi ex verbis Aristotelis [ideo est considerandum quod intentio Aristotelis (Vat)] de intellectu agente imo et universaliter de parte intellectiva non est manifesta, cuius signum est diversitas expositionum, nam inter expositores antiquos et inter expositores noviores invenitur controversia in exponendo Aristotelis verba. Unde et quaelibet supradictarum opinionum nititur verba Aristotelis ad suam intentionem confirmandam trahere. Cum igitur intentio Aristotelis circa hanc materiam adeo sit occulta quod ad plenum et praecise comprehendi non potest quid de hoc ipse sensit propter sui sermonem brevitatem et obscuritatem, arguere contra praedictam positionem ex verbis Aristotelis non est multum efficax via, praesertim cum verba ipsius non incongruenter trahi possent ad hanc

(f. $92 \mathrm{vb}$ ) positionem si quis vellet diligenter intendere. Ad praesens tamen sufficiat ostendere quod verba Aristotelis inducta non repugnant praedicto modo ponendi.

Ad illud ergo quod primo inducitur quod intellectus agens et possibilis sunt duae differentiae in anima dicendum est quod ex hoc non potest efficaciter argui guod sint duae potentiae; nam non omnis differentia in anima facit vel arguit 
diversitatem potentiarum. Unde et Aristotelis numquam invenitur loqui de intellectu nisi tamquam de una potentia. In hac tamen una potentia possunt accipi plures differentiae : eadem enim potentia intellectus dicitur in potentia et in actu, et dicitur practica et speculativa, licet diversimode sumpta. Similiter igitur una et eadem potentia intellectus dicitur et agens et possibilis, sicut dicitur movens et mota, et activa et passiva secundum supradictum modum. Et secundum quod est possibilis, omnia fieri; secundum vero quod est agens, et omnia facere. Et secundum quod est agens habet se sicut ars; secundum vero quod est possibilis habet se sicut materia, licet haec similitudo artis et materiae ad intellectum possibilem et agentem non sit accipienda quantum ad omnia. Unde et secundum Themistium, ut supra dictum est, intellectus agens non est ars materiae exterioris sicut aedificativa respectu lignorum, sed investitur toti potentiae intellectivae ac si ars aedificitiva esset in lignis. Sic igitur intellectus agens et possibilis sunt quidem duae differentiae in anima, non tamen diversae potentiae, sed una duplici modo accepta.

Ad id quod dicitur secundo quod anima est sicut tabula rasa in qua nihil est scriptum, dicendum quod anima semper est actu intelligens secundum actum quoddam incompletum qui dicitur potentia [universalis (Vat)], etiam dici potest habitus, non quidem acquisitus sed naturaliter inditus, et quod iste actus est animae connaturalis. Ideo non dicitur animam esse in potentia ad istum actum, sed est in potentia ad actum completum. Quantum igitur ad actum nihil est actu antequam intelligat, sed est sicut tabula rasa in qua nihil est scriptum; quantum vero ad actum incompletum est anima in actu antequam intelligat, et per eamdem potentiam dicitur animam non esse aliquid actu, et esse omnia in actu antequam intelligat, diversimode tamen sumpta. Ad id autem quod additur, quod praedicta videtur incidere in dogmata Platonis, dicendum est quod platonicorum dogmata quae non contrariantur veritati accipienda sunt; et ideo Platonis doctrina, in his quae sanae doctrinae minime repugnant, respuenda et contemnenda non est, praecipue cum inter philosophos tantae fuerit excellentiae Plato ut a beato Agustino dicatur philosophorum nobilissimus. Dicit etiam Augustinus quod eius doctrina maxime appropinquavit ad fidem christianam inter omnes doctrinas philosophorum, propter quod non immerito ipse et plures alii doctores sacri Platonis doctrinam secuti sunt assumentes quae in ea invenerunt fidei consona, commutantes vero in melius quae invenerunt fidei adversa. Posuit autem Plato animas praeexistere corporibus, et quod ante unionem ad corpus habuit anima cognitionem actualem, sed ex unione ad corpus obliviscitur eorum quae prius novit; in actu remanet tamen in ipsa cognitio habitualis, quae dum per doctrinam et sensibilia excitatur, in actum reducitur; et sic nostrum discere est teminisci. Sed haec opinio non est vera: non enim anima praeexistit antequam corpori uniatur, et per consequens nullam habet cognitionem; unde nostrum discere non est reminisci. Nihil 
tamen horum sequitur ad positionem praedictam de intellectu agente: non enim ponit scientiam innatam animae quae sibi infuit ante corporis unionem; et per consequens non ponit quod discere est reminisci. Ponit tamen quod animae in sui productione communicantur quaedam aptitudines naturales ad scientiam, per quas movet se ad intelligendum in actu; et hoc modo ponere scientiam innatam et habitualem, scil., secundum idoneitatem et aptitudinem, quae est actualitas quaedam incompleta, non est inconveniens; immo videtur esse necessarium hoc dicere si considerentur illa quae de potentiis animae dicta sunt in quaestione de voluntate. Et sic patet quod ista positio non incidit in errorem platonicorum sed [evacuat errorem eorum et assequitur positionem doctrinae antiquorum catholicorum doctorum (Vat)].

Ad illud quod tertio dicitur quod phantasmata sunt animae sicut sensibilia dicendum est quod, licet intellectus moveatur ex se, nihilhominus tamen movetur a phantasmatibus per modum excitationis. Ad hoc autem quod aliquid moveat aliud hoc modo requiritur quod hic quod movet sit coniunctum ei quod movetur, et quod sit in actu secundum aliquid quod habeat convenientiam et habitudinem aliquam ad id secundum quod illud quod movetur natum est esse in actu. Phantasia autem, cum sit potentia quaedam ipsius animae, naturalem coniunctionem habet cum intellectu et immediatum ordinem ad ipsum. Cum igitur phantasia sit in actu secundum aliquid quod habet convenientiam et habitudinem aliquam cum eo ad quod intellectus natus se movere, tunc intellectus excitatur et inclinatur ut se moveat ad actualem cognitionem illius. Et eodem modo sensibilia movent sensum per modum excitationis et inclinationis. Sensibilia enim immutant organa sensuum, quibus immutatis, propter coniunctionem organi cum potentia et propter similitudinem illius immutationis quae facta est in organo cum aptitudine quae est in sensu, sive cum eo ad quod sensus natus est se movere, sensus ipse inclinatur et excitatur ut se moveat ad cognitionem actualem. Et ideo verum est quod phantasmata sunt animae sicut sensibilia; sicut enim sensibilia movent sensum, sic phantasia intellectum, scil., per modum excitationis et inclinationis. In hoc tamen est disimilitudo: quod sensibilia movent ipsam potentiam sensitivam mediante immutatione organi, quae est alia ab actu sentiendi; phantasmata vero movent intellectum non mediante aliqua immutatione quae sit alia ab actu intelligendi. Et ideo melior est similitudo si diceretur quod sic se habent phantasmata ad intellectum, movendo ipsum, sicut se habent immutationes organorum ad potentia sensitivam. Et de sensibus quidem videtur esse intentionem beati Augustini in VI de Musica; similiter autem et XII super Gen. ad litt.: dicit quod sensus ipse format species. De sensu autem et intellectu expresse dicit Boetius in V de Consolatione et VI, ubi exclusa opinione Stoicorum, et ostenso quomodo anima se habet active in cognoscente tam secundum sensum quam secundum intellectum, adiungitur quod ad hoc ut anima se moveat ad sentiendum indiget excitationem sensibilium, 
sic dicens: praecedit tamen excitans ac vires animae movens, vivo in corpore passio cum vel oculus ferit, vel vox auribus instrepit. Tum mentis vigor excitus, quas intus species tenet, ad motus similes vocans notis applicat exteris introrsumque reconditis formis miscet immagines. Intendit autem Boetius per formas et species istas reconditas, idoneitates et aptitudines naturales quae essent actualitates quaedam incompletae. Sensus itaque excitatus per immutationes organi corporei, per illas aptitudines movet se ad actus completos qui habent similitudinem cum immutationibus organorum, et inter imagines et immutationes organorum miscentur et coniunguntur formis et illis aptitudinibus reductis in actum completum ita quod est ibi simul duplex actualitas, scil., immutatio qua organum immutatur ab obiecto, et immutatio sensus qua movet se, quae proprie dicitur sensatio. Et immutatio quidem organi est magis materialis, immutatio vero sensus magis formalis. Licet autem sit duplex actualitas et immutatio, tamen propter coniunctionem sensus et organi, et immutatio organi redundat in sensum, et immutatio sensus concomitatur organo, propter quod sunt quidem una immutatio tum ratione coniunctionis tum ratione similitudinis; et hoc intendit Boetius cum dicit quod imagines miscentur formis: ideo et possunt dici una sensatio. Unde et communiter ipsam immutationem organi solet dici sensatio propter hoc quod sine huiusmodi immutatione non sit sensatio. Aristoteles etiam magis loquitur de immutatione organi quae magis est manifesta, non distinguens eam ab immutatione sensus. Similiter Augustinus qui in VI de Musica distinguit operationem sensus $a b$ immutatione organi; in XI libro de Trinitate c. 2, impressionem quae fit in orga110 visus a re visibili visionem nominat, non distinguens immutationem organi $a b$ operatione sensus quae est magis occulta. Si itaque sensibilia vel ipsae immutationes organorum a sensibilibus movent sensum solum excitando, sensus autem excitatus movetur ex se, multo magis hoc dicendum est in intellectu, scil., quod phantasmata movent intellectum solum excitando, intellectus autem excitatus movet se ad actualem cognitionem et coniungitur actio vel operatio cum phantasmate, ita quod simul est immutatio intellectus quae est intelligere cum immutatione phantasiae quae est ipsum phantasma, ut nomine phantasmatis intelligatur non idolum quod imprimitur in organo phantasiae, sed ipsa operatio virtutis phantasticae. Ab hac enim intellectus excitatur immediate, et inde est quod nihil sine phantasmate intelligit anima dum est corpori coniuncta; sicut nec sensus aliquid percipit sine immutatione facta in organo; et sicut phantasia excitat intellectum; sic et una potentia sensitiva excitat

(f. $93 \mathrm{rb}$ ) aliam ad quam habet ordinem naturalem. Ad hanc autem excitationem intellectus a phantasia non requiritur (quod) intellectus aliquam virtutem tribuat phantasmatibus, quamvis ignobiliora sint intellectu, quia non oportet ad hoc quod aliquid moveat aliud per modum excitationis quod sit eo nobilius; sufficit autem quod ad ipsum habeat coniunctionem et ordinem, et quod sit in actu se- 
cundum aliquid conveniens vel aliquam habitudinem habens ad id secundum quod natum est esse in actu id quod excitari dicitur. Sic autem se habet phantasia facta in actu ad intellectum; sicut igitur sensus movet se ad suam operationem et tamen excitatur ab immutatione organi, sic intellectus excitatur quidem a phantasia, tamen ex seipso movetur ad actum intelligendi multo magis quam sensus ideo quia intellectus. Post supradictos versus in quibus ostendit de sensu quomodo excitatus movet se, subaudit de intellectu dicens quod si in corporibus sentiendis quamvis afficiantur instrumenta sensuum forinsecus obiective, qualitates autem agentis quia vigorem passio corporis antecedit quae in se actum mentis provocet excitet quia intimum quiescentis intrinsecus formis assentiendis, inquam corporibus, animus non passione insignitur sed ex sua subiectam corpori passionem, quanto magis ea quae anima corporum affectionibus soluta in distinguendo non adiecta extrinsecus sequitur, sed actum suae mentis. Similiter autem et Simplicius in praedicamentis dicit: attentione autem est dignum ne forte intelligere et videre non sint pati solum et informari, sed habeant quamdam intrinsecus excitatam operationem secundum quam fit perceptio et nihil mirum existimo si commixtus aliquid in his accidit, nam commune est quidem facere, solum hoc vero pati; hoc vero simul facere et pati sicut intelligere et videre. Et Damascenus dicit in tractatu de duplicibus, lib. X quod phantasticum et sensitivum sunt possibiles operationes vel passiones operativae; de intellectiva vero quae est actio intellectus dicit quod est operatio sicut autem ipse dicit II lib. c. XXIII : operatio est vere motus affectivus, affectivus autem dicitur quod ex seipso movetur. Apparet igitur quod licet intellectus moveatur ex se, tamen sensus sunt necessarii ad acquirendam cognitionem intellectualem quia dum anima est corpori coniuncta nihil intelligit nisi excitata per sensum et sensibilia. Ad id autem quod dicitur quod secundum positionem praedictam scientia nostra non causatur a rebus, dicendum quod illud principaliter est causa scientiae in nobis quod principaliter animam movet ad cognoscendum. Anima autem movetur principaliter a Deo quidem efficienter qui ipsam producit; a seipsa vero formaliter, a sensibus vero et a sensibilibus movetur non principaliter sed per modum excitationis cuiusdam, ut dictum est. Et ideo causa scientiae principaliter in nobis est Deus et ipsa anima; res autem sensibiles sunt causae non principaliter sed aliquo modo. Unde et illi qui ponunt intellectum agentem esse aliam potentiam ab intellectu possibili, et quod per ipsum abstrahuntur species a phantasmatibus dicunt quod sensibilis cognitio non est totalis et perfecta et principalis causa nostrae cognitionis et intellectualis, sed est concausa vel causa sive instrumentum; principalis autem causa est intellectus agens. Ex hoc enim provenit error accademicorum dicentium quod nihil contingit, quia cum ponerent scientiam causari principaliter a rebus sensibilibus, oportebat secundum illos cognitionem transmutari secundum transmutationem rerum. Scientia autem est cognitio intransmutabilis. Ad hunc autem errorem excludendum Plato posuit causari 
scientiam in nobis per participationem idearum, et si quidem has ideas extra Deum posuit, inconveniens et falsa fuit eius opinio. Si autem eas posuit in divino intellectu, sic veritatem habet, quod dixit beatus Augustinus in pluribus locis: ait autem quod omnia cognoscimus in luce primae veritatis et in rationibus aeternis. Prima autem veritas Deus est; rationes vero aeternae sunt ideae rerum in Deo. In istis igitur dicitur animam omnia cognoscere, quia cognoscit per aptitudines ab his rationibus derivatas et sibi naturaliter inditas et semper in ea manentes, sicut dicuntur videri in sole quae videntur in lumine derivato a sole. Unde ipsa potentia intellec-

(f. 93 va) tiva cum suis aptitudinibus est lumen quoddam quod Deus accendit in anima in sua productione. Et ad hoc possunt trahi verba Aristotelis qui dicit quod intellectus agens est habitus quidam sicut lumen. Ipsa enim intellectualis potentia est quaedam habitualis notitia quae semper inest animae et est lumen in quo continentur intelligibilia, quia per huiusmodi potentiam se movet anima ad spsorum cognitionem actualem. Apparet igitur ex dictis unde causatur scientia in nobis, quia principaliter sicut a movente per modum efficientis causatur a Deo; et ideo ipse dicitur intellectus agens in quo, sicut in cognitionis causa et principio, omnia cognoscuntur. $\mathrm{Ab}$ anima autem vero causatur scientia principaliter in quantum per potentiam sibi a Deo inditam se movet formaliter ad cognitionem; et ideo et in ipsa ponitur intellectus agens tamquam aliquid ipsius, licet proprie loquendo non agat per modum efficientis; large tamen accipiendo efficiens etiam huiusmodi agens efficiens dicitur. Movet etiam anima seipsam per potentiam intellectivam aliquo modo efficienter; facta in actu quantum ad alia ut quantum ad conclusiones, sicut supra etiam de voluntate dictum est; et propter hoc aliqui posuerunt intellectum agentem esse habitum principiorum. Hinc etiam est quod si aliquis ordinate interrogatur de aliquibus, quae tamen non ante intellexit, verba respondet, in quantum per unum cognitum movet se ad illud quod ordinem habet ad primum, excitatus et admonitus per verba interrogantis vel et signa. A rebus vero causatur scientia in nobis dupliciter: uno modo in quantum mediantibus potentiis sensitivis, ipsae res sensibiles excitant intellectum ad hoc ut se moveat; alio modo in quantum anima movetur ut ipsis rebus assimiletur et conformetur in actu; et sic sunt causa cognitionis per modum termini; et inde sequitur quod anima assimilatur rebus non autem res animae assimilantur. Unde eo modo quod finis dicitur movere mechanice, dicitur et id quod est obiectum nostrae cognitionis causare ipsam cognitionem, quod intelligendum est de cognitione speculativa. Et hoc modo potest intelligi quod dicit Augustinus IX de Trin. c. XII : liquido tenendum est quod omnis res quamcumque cognoscimus congeneret in nobis notitiam sui. $A b$ utroque ergo paritur notitia: et a cognoscente et a cognito; notitia enim actualis est similitudo cognoscentis et cogniti, et secundum hoc paritur ab utroque. Tamen a cognito paritur solum ex hoc quod est eius similitudo; a cog- 
noscente vero et quia est similitudo eius in quantum in cognoscente praeexistit, et etiam quia cognoscens movet se ad actualem notitiam secundum illam habitualem quae etiam est similitudo ipsius cogniti, licet incomplete. Deus enim impressit animae et indidit quasdam spirituales et incompletas similitudines rerum cognoscibilium per quas movet se ad similitudines completas. Et secundum hoc dicitur moveri a rebus in quantum se movet ut assimiletur illis aeternis rationibus a quibus res ipsae derivatae sunt et aptitudines animae impressae et inditae. Dicitur etiam creari scientia in doctore in quantum per signa sensibilia movetur et excitatur aliquis ad considerandum aliquid cuius habitualis notitia praeexistit in ipso, quae est quaedam idoneitas; unde dicit Boetius III de Consolatione... verbi quod excitatur ventilante doctrina...

Ad illud vero quod dicitur quarto, quod per hanc positionem tollitur abstractio intellectus, dicendum quod haec positio tollit abstractionem quae dicitur fieri $\mathrm{ab}$ aliquibus per depurationem phantasmatum; abstractionem non tollit absolute, sed negat abstractionem quae dicitur fieri ab aliquibus. Non enim dicitur intellectum abstrahere a phantasmatibus ea depurando et illustrando, sed quia ab ipsis phantasmatibus excitatus, puriori modo cognoscit quam phantasia. Unde licet phantasia cognoscat particulariter, intellectus tamen cognoscit universaliter, et licet phantasia per se sit cognoscitiva accidentium, intellectus tamen ad ipsam substantiam attingit. Haec autem abstractio intellectus ex ipsa potentia intellectualis procedit, quae, secundum aptitudines inditas, primo habet ordinem ad intelligendum universalia et ipsa particularia, et prius ad intelligendum substantiam quam accidens. Ad id autem quod dicitur quod non potest salvari secundum hanc positionem quomodo illud quod est potentia intelligibilis fiat actu intelligibile per intellectum agentem, dicendum quod hoc potest convenienter salvari. Sic enim dicitur aliquid fieri actu intelligibile quod erat intelligibile in potentia, sicut dicitur aliquis fieri similis actu cum prius esset similis in potentia, facta mutatione

(f. $93 \mathrm{vb}$ ) non in potentia sed in alio. Unde cum anima movet se ad actualem cognitionem excitata a phantasmatibus, id quod erat potentia intelligibile fit actu intelligibile, non quia aliquam virtutem tribuat ei quod est potentia intelligibile, sed quia facit se de potentia in actum intelligendi. Unde sic denominatur aliquid intelligibile $a b$ intellectu sicut dicitur intelligibile per potentiam vel actum ipsius intellectus. Et hoc modo illud quod facit intellectum de potentia intelligentem actu intelligentem dicitur per hoc facere illud quod est potentia intelligibile actu intelligibile. Et ideo et Aristoteles non ponit intellectum agentem in phantasia sed intellectum possibilem ad quem se habet sicut ars ad materiam, licet sine phantasmatibus non agat. Exemplum autem quod inducit de lumine respectu oculorum, si recte intelligatur confirmat quod dictum est; lumine enim facit potentia colores actu colores, sicut dicit Johannes Grammaticus: non quia exhibeat existentiam coloribus, sed solum videri; in tenebris enim sunt potentia visibiles, 
sed per lumen sunt actu visibiles, non quod per lumen aliqua virtus tribuatur coloribus, sed magis ei quod est susceptivum speciei coloris. Similiter intellectus agens facit res actu intelligibiles non quia virtutem tribuat rebus, sed quia per ipsum anima se movet ad actualem rerum cognitionem.

Ad illud vero quod inducitur quinto, quod secundum hanc positionem frustra unitur anima corpori, dicendum est quod frustra est quod ordinatum est ad aliquem finem et illum non assequitur. Finis autem ultimus et principalis et quidem extrinsecus unionis animae rationalis ad corpus est divina bonitas propter quam communicandam et repraesentandam Deus ipse instituit gradus diversos viventibus creatis ut esset aliqua creatura spiritualis, aliqua corporalis, aliqua vero ex utraque composita, medium et vinculum utriusque. Finis autem propinquus et [quidem (Vat)] intrinsecus est perfectio corporis et animae. Ex hac enim unione perficitur et corpus et anima, sed tamen differenter: corpus enim ex unione perficitur quia per animam sortitur et esse et vivere et moveri; unde dicit Philosophus in II de anima quod anima est causa et principium corporis tripliciter, scil., sicut forma et sicut motor et sicut finis; anima vero perficitur ex hac unione non quia corpus sit ei causa essendi et operandi, nam et aliae formae quae non sunt subsistentes non sic perficiuntur per suam materiam in esse aut in operari, licet non sint nec operentur nisi in materia, tamen quia fiunt unum secundum essentiam et quia aliquo modo et cooperantur; nam quo sanamur est duplex : sanamur enim sanitate et corpore, sicut dicitur in II de anima. Unde et esse et operari est totius compositi utriusque. Tamen forma est principaliter causa et ratio; multo magis igitur anima, quae est forma per se subsistere potens et per consequens operari non perficitur ex unione ad corpus quia corpus sit ei causa essendi et operandi, licet quamdiu est coniuncta corpori et esse et operari non habeat sine communicatione corporis; sed dicitur perfici anima ex unione ad corpus [in quantum corpus administrando (Vat)] assequitur divinam similitudinem, scil., dignitatem causalitatis eo modo quo movens et agens dicitur perfici ex hoc quod movet et agit ad perfectionem alterius. Anima igitur perfectionem suae operationis non acquirit principaliter per corpus et per sensus corporeos sed a Deo efficienter et a seipsa formaliter; non tamen frustra corpori unitur quia non ad hoc principaliter unitur corpori ut per ipsum suam perfectionem acquirat, sed magis ut corpus perficiat. Ex hoc tamen ipso quod perficit corpus ut forma ipsius, corpus cooperatur ad animae perfectionem aliquo modo; nec tamen sequitur si anima unitur corpori ut ipsum perficiat non ut per ipsum perficiatur principaliter, quod anima sit propter corpus; non enim finis animae est perfectio corporis sed assimilatio ad id quod est et anima et corpore melius: hic autem est Deus ipse. Si autem dicitur quod inconveniens fuit animam uniri corpori corruptibili ad ipsam administrandam cum tale corpus animam deprimat et aggravet in operando quae liberior esset $a b$ illo separata, dicendum est quod istud inconveniens illis imminet 
qui ponunt animas post separationem a corpore corruptibili perpetuo sine corpore remanere, vel illis qui ponunt animas per quasdam circulationes vel revolutiones ad huius corporis incessanter iterato redire, quorum utrumque veritati repugnat. Catholice autem sentientibus nullum inconveniens imminet; haec enim unio fit ex intentione agentis qui sic ordinavit et instituit ut anima uniatur ad tempus corpori corruptibili secundum materiam in quo si rectitudinem servet cum auxilio gratiae suae quod ei aptavit illud corpus in meliorem conditionem sit immutandum quandoque, ut sine illo gravamine et impedimento animae amministretur ab ipsa perpetuo. Non est autem inconveniens [hoc fine (Vat)] animam uniri corpori.

(f. 94 ra) corruptibili quamvis ex ipso aggravetur. Quare autem Deus non a principio tale corpus animae aptavit quod sine ullo impedimento possit amministrari ab ipso perpetuo, non alia ratio est nisi quia sic voluit ad manifestationem suae bonitatis. Si autem aliquis dicere velit quod tale corpus fuit datum animae ante peccatum primi hominis cum esset immortale, dicendum est quod, sicut convenienter ponitur, corpus hominis ante peccatum immortale fuit, non per meritum sed per donum quoddam naturae superadditum; alioquin immortalitas illa per peccatum non fuisset sublata. Et praeterea licet esset illud corpus immortale, erat tamen animale, et si rectitudinem homo servaret tempore divinitus praefinito, immutandum erat in meliorem statum in quo anima fuisset adhuc in operando libenter tamquam magis perfectam et plenum dominiun corporis habens. Talem autem immutationem futuram speramus in resurrectione generali non quantum ad omnes sed quantum ad electos qui ipsum in corpore corruptibili ex dono gratiae meruerint. Apparet igitur ex dictis quid dicendum sit de intellectu agente. Et est sciendum quod secundum modum ultimo modo tactum, intellectus agens ex eadem ratione ponitur in angelis, sicut in anima separata, sicut ei coniuncta; videtur enim rationabiliter esse dicendum quod anima a principio suae productionis accepit a Deo quidquid ei convenit naturaliter secundum quodcumque statum, ita quod cum est a corpore separata nihil sibi de novo imprimitur per quod se moveat ad agendum, licet moveat se per potentiam intellectivam et aptitudines a principio suae productionis ei naturaliter inditas. Tamen per illas movet se liberius cum est separata quam cum est in corpore corruptibili a quo deprimitur coniuncta, quia, sine aliqua excitatione facta a rebus per sensus sed per solam unionem volentis vel intentionem sicut convenienter dicitur etiam de angelis. Unde si quis aggravationem et depressionem animae a corpore corruptibili velit per quamdam similitudinem oblivionem vocare, potest manifestari quod anima ex unione ad corpus corruptibile oblivionem patitur in quantum non ita se movet prompte et perfecte sicut si non esset tali corpori unita; et similiter consideratio actualis ad quam discendo pervenit ex quadam similitudine remisniscentia dicitur, quia sicut in reminiscendo accidit difficultas quaedam et requiritur discursus quidam ordina- 
tus, sic et in discendo. Et forte secundum hanc similitudinem vel aliquam aliam quae assignari posset assignat Boetius in hoc. Ac quaeritur in libro de Consolatione iilud quod a Platone dicitur de oblivione et reminiscentia in anima. Quaecumque autem dicta sunt ad declarationem ultimi modi loquendi de intellectu agente sine praeiudicio cuiuscumque opinionis accipiantur non nisi declarando quae probabiliter inquirendo dicuntur, praecipue cum sit res occulta et ardua circa quam et magna ingenia vacillasse invenitur.

Ad illud igitur quod obiicitur in contrarium: intellectus non est aliquid animae quia secundum Philosophum in III de anima est substantia actu ens, dicendum est quod sicut supra dictum est, non ad plenum patet quid Aristoteles de intellectu agente opinatus fuerit. Nam praecipui expositores ipsius, sicut Alexander et Averrois, dixerunt fuisse de intentione eius quod intellectus agens sit aliqua substantia inmmaterialis, alia ab anima, quae est eius corporis forma. Alii vero dicunt quod intentio Aristotelis fuit quod sit potentia quaedam animae. Er ideo ex verbis Aristotelis non potest multum efficaciter argui in hac materia. Sustinendo tamen ultimo tactum [supra (Vat)] de intellectu agente potest dici, quantum ad auctoritatem philosophi primo inductam, quod intellectus agens dicitur substantia actu ens quia est ipsa essentia animae et penfecta per potentiam intellectivam quae intellectus agens vocatur, et est quaedam actualitas indita animae naturaliter quamvis perfectibilis per actum completiorem; magis enim proprie dicitur agens ipsa animae substantia perfecta per huiusmodi potentiam quam ipsa potentia. 